\title{
Calculation of the Cross Section Active Area for a Polymeric Spiral Wound Reverse Osmosis Membrane
}

\author{
MIHAELA-ELENA DASCALU ${ }^{1}$, FLORIN NEDEFF ${ }^{*}$, VLAD CIUBOTARIU², JUAN ANTONIO LOPEZ-RAMIREZ3 ${ }^{3}$ ION SANDU4,5, \\ 'Vasile Alecsandri University of Bacau, Department of Environmental Engineering and Mechanical Engineering, 157, Calea \\ Marasesti, 600115, Bacau, Romania \\ ${ }^{2}$ Vasile Alecsandri University of Bacau, Department of Industrial Systems Engineering and Management, Calea Marasesti 156, \\ 600115, Bacau, Romania \\ ${ }^{3}$ Universidad de Cadiz, Departamento de Tecnologías del Medio Ambiente, CASEM - Polig. Rio San Pedro, s/n. 11510 Puerto Real, \\ Cadiz, Spain \\ ${ }^{4}$ Alexandru Ioan Cuza University of Iasi, ARHEOINVEST Interdisciplinary Platform, Carol I Blvd., 22, 700506 lasi, Romania \\ ${ }^{5}$ Romanian Inventors Forum, Sf. Petru Movila St., no. 3, BI. L11, Sc. A., Ap. 3, Et. III, Ap.3, 700089, Iasi, Romania
}

Cross flow filtration is the typical way that water is filtered in membrane technology; that means that feed solution passes tangencially over the membrane and rejected components are washed away of the membrane by the rejected stream. In such a way, that minimal solids building up and at constant low flow resistance are achieved. In this paper, a calulation method regarding to the value of cross-section active area for a polymeric spiral wound reverse osmosis (RO) membrane is presented, in order to obtain the value of the cross-flow velocity of the system. This velocity is needed to improve the knowledge fouling mechanisms and it is not easy to know without obtaining the cross section area. To determine cross-section area of a RO polymeric spiral wound membrane a series of calculations were performed to obtain the initial values of some parameters. The mathematical calculation was also achieved with the Roll Length program. Based on the results obtained, it was concluded that only $65.36 \%$ of the total cross-section of the membrane is useful to cross flow and it was possible to determine the active cross-section of filtration with a value of $1,915.4 \mathrm{~mm}^{2}$, for the membrane studied. This methodology allows the calculation for any RO spiral membrane.

Keywords: reverse osmosis (RO), polymeric membrane, spiral configuration, cross-section, cross flow velocity (CFV)

Filtration is a method of separating solids from fluids following flow through permeable porous media, called filter media or filters [1-4]. The use of membrane technology offers a number of advantages such as $[1,5$, $6]$ : low energy consumption, the possibility of continuous operation, simple operating conditions, the possibility of coupling these techniques with other classical separation processes, investment and operating costs accessible, etc. For example, optimal solutions that combine conventional processes with advanced technologies, such as membrane filtration, guarantee a high level of flexibility and superior water quality $[1,6,7]$.

In general, a membrane can be considered a barrier separating two compartments. From a filtration point of view, the membrane is a selective filter medium which allows the preferential transfer of a particle, molecule, phase or substance under the action of a driving force [ $[$, $2,8]$.

The membranes are made of various types of materials: organic (polymer), inorganic (metal, ceramic, glass, active carbon), mixed (hybrid polymers, composites: ceramicpolymer etc.) [1,2]. Membrane characterization is based on the study of physico-chemical properties such as [1, 2, 9-11]: ion exchange capacity, water retention, water content, film thickness, thermal and chemical stability, porosity, etc.

RO is one of the most effective water treatment methods for water containing hazardous contaminants, such as nitrates, nitrates, mercury, arsenic, lead, pesticides, fluorides, etc. [1, 12].

The RO process is applied by cross flow, which means that the permeable flow is directed perpendicular to the feed stream. So, the impurities remain in the feed side, which gradually reduces its volume, leaving the membrane system in the form of a concentrated residual flow $[1,10$, 13]. Cross-flow filtration is applied for RO, butalso for other processes such as nanofiltration, ultrafiltration and microfiltration, depending on the size of the membrane pores $[1,13]$.

Membranes are made of different materials. The first RO membranes were made of celluloses and their derivatives. These were low cost hydrophilic polymers and had low adsorption tendencies $[1,10,14]$. Nowadays, the most used polymer is aromatic polyamide, becoming the standard in desalination industry, but the use of nanotechnology is increasing and improving current polyamide membranes. Besides, new trends are intended to use inorganic membranes, like ceramic membranes with very interesting results. [1, 11, 14, 15].

In this paper authors presenta mathematical calculation regarding the active filtration section of a polymeric RO membrane in order to determine the cross-flow velocity, required value in multiple experimental researches.

\section{Experimental part}

In order to determine the cross-flow velocity (CFV) of a RO polymer membrane, it is necessary to calculate this parameter according to the feed flow and the cross-section of the spiral membrane using the relation (1). The CFV is notconstant over the entire length of the spiral membrane, since its function over time and length is not the same [1]:

$$
C F V=\frac{Q_{a}}{s_{a}}=\frac{Q_{p}+Q_{r}}{s_{a}} \quad(\mathrm{~m} / \mathrm{s})
$$


where:

$\mathrm{O}$. is the feed rate of the membrane $\left(\mathrm{m}^{3} / \mathrm{s}\right)$,

$Q_{a}=Q_{p}+Q_{r}$

$\mathrm{Q}_{\mathrm{p}}$ - flow rate of permeate $\left(\mathrm{m}^{3} / \mathrm{s}\right)$;

$Q_{r}^{p}$-concentrate flow rate $\left(\mathrm{m}^{3} / \mathrm{s}\right)$;

$\mathrm{S}^{r}$-cross-section area of the membrane $\left(\mathrm{m}^{2}\right)$.

Mathematical calculation was also achieved with the use of the software Roll Length program (a mathematically simplified program calculation that makes it possible to obtain results) in the following steps: $[1,9,10]$ :

1.From the data received from the manufacturer we have the value of the inner diameter $\left(D_{0}\right)$ and outer diameter $\left(D_{1}\right)$ and the predetermined length of the membrane forming material $\left(L_{p}\right)[1]$ :

$$
\begin{aligned}
-D_{0} & =19.10 \mathrm{~mm} ; \\
-D_{1} & =64 \mathrm{~mm} ; \\
-L^{2} & =1.570 \mathrm{~mm} .
\end{aligned}
$$

2.The membrane consists of the following layers (fig. 1), their thickness has been measured at the Environmental Technology Laboratory of the Department Environmental Technologies at University of Cadiz, Spain and has the following values [1]:

-membrane separator layer $=0.71 \mathrm{~mm}$;

-membrane layer $=0.14 \mathrm{~mm}$;

-permeate collector layer $=0.23 \mathrm{~mm}$;

-membrane layer $=0.14 \mathrm{~mm}$;

3.Using the Roll Length program (fig. 2), the total length

(Ltot) of the layers forming the membrane was calculated

using [1]:

-total thickness of layers forming the membrane spiral

$\mathrm{h}=1.22 \mathrm{~mm}$;

-inner diameter $(D 0)=19.10 \mathrm{~mm}$; -external diameter $(\mathrm{D} 1)=64 \mathrm{~mm}$.

The total length (Ltot) of the material is obtained, $\mathrm{L}$ tot $=$ $2.402 \mathrm{~mm}$, which means a number of 18.4 spirals (fig. 3).

4.Knowing the total length (Ltot) of the material (s) it was possible to calculate the cross-section of each layer constituting the RO membrane, as follows [1]:

-S1 membrane separator layer $=0.71 \mathrm{~mm} \times 2,402 \mathrm{~mm}$ $=1705.42 \mathrm{~mm}^{2}$;

-membrane layer S2 $=0.14 \mathrm{~mm} \times 2,402 \mathrm{~mm}=336.28$ $\mathrm{mm}^{2}$;

-S3 collector layer;

-permeate collector layer $=0.23 \mathrm{~mm} \times 2,402 \mathrm{~mm}=$ $552.46 \mathrm{~mm}^{2}$

-S4 membrane layer $=0.14 \mathrm{~mm} \times 2,402 \mathrm{~mm}=336.28$ $\mathrm{mm}^{2}$;

It results a total filtration cross-section with the value of $\mathrm{S}_{\text {tot }}=2$ 930,44 $\mathrm{mm}^{2}$ [1].

5. Knowing the preset length of the materials, $L_{p}=1.570$ $\mathrm{mm}$ and total length $\left(\mathrm{L}_{\text {tot }}\right)$ of the material (layers) $\mathrm{L}_{\text {tot }}=$ $2.402 \mathrm{~mm}$ it could be determined that only $65.36 \%$ of the calculated Ltot was used, so the surface between $D_{0}$ and $D_{1}$ would contain only 12.03 spires [1].

6.By determining that only $65.36 \%$ of the total crosssection of the membrane is used, we can determine the useful filtration cross-section or the active filter crosssection $\mathrm{Sa}=1915.4 \mathrm{~mm}^{2}$ [1].

From these data it follows that the cross-section of the voids among the spirals is [1]:

$$
\mathrm{S}_{\text {gol }}=\mathrm{S}_{\text {tot }}-\mathrm{S}_{\mathrm{a}}=1015.04 \mathrm{~mm}^{2}
$$

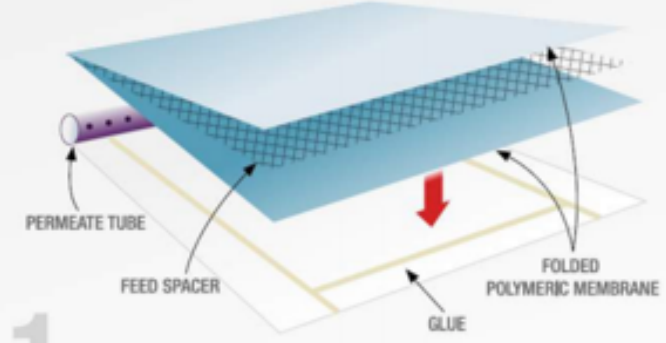

Membrane leaf being glued onto the permeate carrier

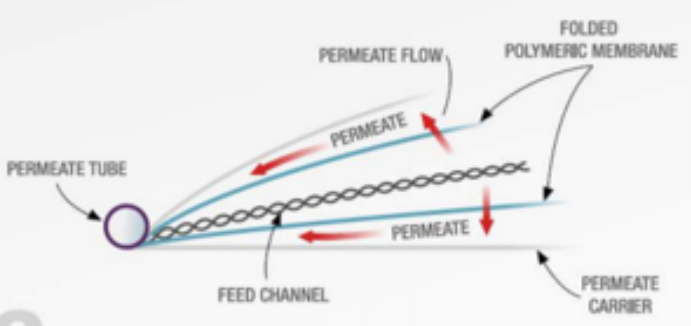

Cross section of a membrane leaf

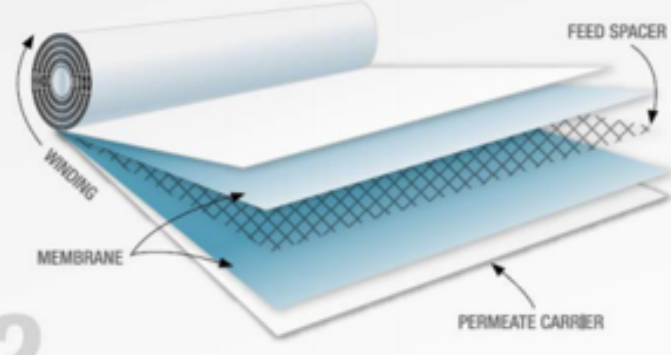

Winding of a spiral element

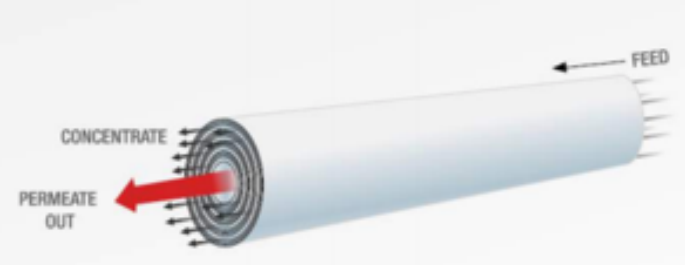

Finished spiral element
Fig. 1. RO spiral wound element conformation

$[1,14]$

$\begin{array}{rlrl}\text { Tape thickness: } \mathrm{h} & =1.22 & \mathrm{~mm} \\ \text { Roll internal diameter: } \mathrm{D}_{0} & =19.1 & \mathrm{~mm} & \mathrm{~mm} \\ \text { Roll external cliameter: } \mathrm{D}_{1} & =64 & \text { Calculate L } \\ \text { Tape length: } \quad \mathrm{L} & =2.4021417938502494 & \mathrm{~m} & \text { Calculate D1 } \\ \text { Number of turns: } & \mathrm{N} & =18.401639344262296 & \\ & \checkmark \text { Use exact formula } & \end{array}$

Fig. 2. Screen capture from the Roll Length Calculator $[1,16]$

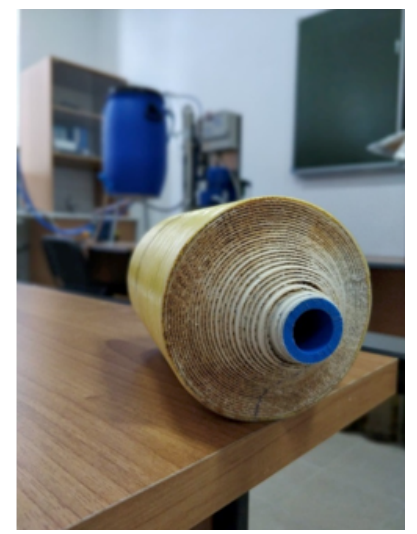

Fig. 3. Cross view of a RO polymeric membrane element to highlight spiral layers 


\section{Results and discussions}

If the void in the membrane would be minimized, other diameters of the membrane would be obtained. This can be done to minimize free space Sgol $=1015.04 \mathrm{~mm}_{2}$. For this purpose, two methods can be applied [1]:

-in the first, knowing the diameter $D_{0}=19.10 \mathrm{~mm}$, it is possible to calculate the surface

$\mathrm{S}_{0}=286.38 \mathrm{~mm}^{2}$. From here, it is also determined $\mathrm{D}_{0^{\prime \prime}}$ the new inner diameter, this being equal to:

$$
D_{0,}=\sqrt{\frac{4(286,38+1015,04)}{3,14}}=40.71 \mathrm{~mm}, \text { iar } \mathrm{D}_{1}=64 \mathrm{~mm}
$$

-in the second, knowing $D_{1}=64 \mathrm{~mm}$, the surface can be calculated, $S_{1}=3.215 .36 \mathrm{~mm}^{2}$. And so $D$ can be determined $D_{1}$, the new outer diameter, this being equal to:

$$
D_{1 \prime}=\sqrt{\frac{4(3215,36-1015,04)}{3,14}}=52.94 \mathrm{~mm}, \mathrm{iar} \mathrm{D}_{0}=19.10 \mathrm{~mm}
$$

\section{Conclusions}

Based on the results obtained of the mathematical calculation regarding the determination of the active filtration section value, it was found that only $63.36 \%$ of the total membrane section was used, from which it follows that the active cross-sectional filtration section $\mathrm{S}_{\mathrm{a}}$ has, in this case, a value of $1915.4 \mathrm{~mm}^{2}$.

This calculation method sums up the calculation sections / steps taken from the literature, as well as its own deductions, which have a number of advantages, such as:

-the use of the Roll Length program, which simplifyes mathematical calculation and makes it possible to obtain results;

-performing a series of calculations to obtain the initial values of some parameters

of the polymeric membrane concerned;

-the possibility to work with the RO membrane under different operating conditions and to calculate the value of the cross flow filtration value;

-the use of these methods / procedures when the value of the active section of a spiral RO membrane filter is not available, and this parameter is required in various experimental research.

\section{References}

1. DASCALU, M.E., PhD thesis: Comparative study between the nanofiltration and reverse osmosis membranes for efficient water treatment, presented in September 25, Bacau -Romania 2018.

2. VIDA-SIMITI, I., Procedee fizico-mecanice de separare a poluantilor, http://w ww.sim.utcluj.ro/stm/dow nload/Procedee_separare/ Cap_5.pdf, UTPRES Cluj-Napoca, 2006.

3. RACOVITEANU, G., Teoria decantãrii si filtrarii apei, Matrix Rom, Bucharest, 2003.

4. STRATHMANN, H., Sustainability Scienceand Engineering, Elsevier B.V., Institute of Chemical Engineering,University of Stuttgart (Germany), vol. 2, ISSN 1871-2711, 2010, DOI 10.1016/S18712711(09)00201-3r.

5. *** Metode moderne in procesarea alimentelor, Capitolul 2 - Tehnici de separere cu membrane, https://www.scribd.com/document/ 98104405/TEHNICI-DE-SEPARARE-CU-MEMBRANE.

6. ROGOVEANU, I., ROBESCU, D. N., Epurarea apelor uzate utilizând tehnologii membranare, Universitatea Politehnica Bucure-ti, Ecoterra, no. 29, 2011.

7.***, https://www.wabag.com/category/innovations/drinking-watertreatment-innovations/;

8. HOTCHKIES, W.J., P.Eng., General Manager - Land Development Systems, ZENON Municipal Systems Inc., 3239 Dundas Street West, Oakville, Ontario L6M 4B2 Canada, September 2000, http:// www.bvsde.paho.org/bvsaidis/cwwa9/hot.pdf.

9. DIEZ GONZALEZ, T., MACORRA GARCIA, C., Revista Tecnologí@ y desarrollo, vol. XII, Universidad Alfonso X El Sabio - Escuela Politecnica Superior Villanueva de la Cañada (Madrid), ISSN: 16968085, 2014.

10. JOHNSON, J., BUSCH, M., , Engineering Aspects of Reverse Osmosis Module Design, Lenntech, https://www.lenntech.com/Datasheets/Engineering-Aspects-of-Reverse-Osmosis-Module-DesignL.pdf, 2009.

11. DASCALU, M.E., VIAS, D.A., NEDEFF, V., LOPEZ-RAMIREZ, J.A., Environmental Engineering \& Management J ournal, 15, no. 7, 2016, p. 1629.

12. DEAC, A., IACOB, C.A., Bulletin of the Transilvania University of Brasov, 10, Special Issue, 2017, p. 59.

13.*** http://www.tetrapak.com/mx/processing/membrane-filtration/ technology.

14. ${ }^{* * *}$ http://synderfiltration.com/learning-center/articles/introductionto-membranes/polymeric-membranes-porous-non-porous/.

15. JON, J., BUSCH, M., Engineering Aspects of Reverse Osmosis Module Design, Lenntech bv, 2009.

16. *** Roll Length Calculator, 2012 edition, http://www.giangrandi.ch/ soft/spiral/spiral.shtml.

Manuscript received: 5.03 .2019 